\title{
Correction to: Prophylactic negative pressure wound therapy after lower extremity fracture surgery: a pilot study
}

Siem A. Dingemans ${ }^{1} \cdot$ Merel F. N. Birnie ${ }^{1} \cdot$ Manouk Backes $^{1} \cdot$ Vincent M. de Jong $^{1} \cdot$ Jan S. Luitse ${ }^{1} \cdot$ J. Carel Goslings ${ }^{1}$. Tim Schepers ${ }^{1}$

Published online: 16 July 2018

(C) SICOT aisbl 2018

Correction to: International Orthopaedics (2018) 42:747-

753

https://doi.org/10.1007/s00264-018-3781-6

The published online version contains a mistake in the author list for the name of the author "J. Carel Goslings" it was incorrectly presented in the HTML version, it should have been presented as:

Family name:Goslings

First name: J. Carel

The online version of the original article can be found at https://doi.org/ 10.1007/s00264-018-3781-6

Tim Schepers

t.schepers@amc.nl

1 Department of Surgery, Academic Medical Center, Trauma Unit, Meibergdreef 9, PO Box 22660, 1100 DD Amsterdam, Netherlands 